\title{
Analysis of Antigens of Mycobacterium leprae by Interaction to Sera IgG, IgM, and IgA Response to Improve Diagnosis of Leprosy
}

\author{
Avnish Kumar, ${ }^{1}$ Om Parkash, ${ }^{2}$ and Bhawneshwar K. Girdhar ${ }^{3}$ \\ ${ }^{1}$ Department of Biotechnology, School of Life Sciences, Dr. Bhim Rao Ambedkar University, Khandari Campus, Agra, \\ Uttar Pradesh 282004, India \\ ${ }^{2}$ Department of Immunology, National JALMA Institute for Leprosy and Other Mycobacterial Diseases, Tajganj, Agra, \\ Uttar Pradesh 282001, India \\ ${ }^{3}$ Shanti Manglik Hospital, Fatehabad Road, Agra 282001, India \\ Correspondence should be addressed to Avnish Kumar; avnishkumar81@gmail.com
}

Received 28 February 2014; Revised 21 May 2014; Accepted 9 June 2014; Published 29 June 2014

Academic Editor: Valeria Rolla

Copyright (C) 2014 Avnish Kumar et al. This is an open access article distributed under the Creative Commons Attribution License, which permits unrestricted use, distribution, and reproduction in any medium, provided the original work is properly cited.

Till 2010, several countries have declared less than one leprosy patient among population of 10,000 and themselves feeling as eliminated from leprosy cases. However, new leprosy cases are still appearing from all these countries. In this situation one has to be confident to diagnose leprosy. This review paper highlighted already explored antigens for diagnosis purposes and finally suggested better combinations of protein antigens of $M$. leprae versus immunoglobulin as detector antibody to be useful for leprosy diagnosis.

\section{Introduction}

Mycobacterium leprae is noncultivable bacteria in artificial media, which is generally grown in cooler region of host especially human beings [1]. We believed that after infection M. leprae facilitates its environment for its survival in host. On entry cell wall, cell membrane and secreted proteins of $M$. leprae would be the first to interact with host immune cells; that is, these proteins can stimulate host immune system. In our opinion, potential peptide antigens which interact with defense cells may be soft target for development of diagnostic tools. Screening of $\operatorname{IgG}, \operatorname{IgA}$, and $\operatorname{IgM}$ response to antigens of $M$. leprae could shortlist the potential candidate antigens. Similar to other living beings, in a structural and functional unit, proteins are elaborate major portion of $M$. leprae cytosol and cell membrane, many of which are able to evoke antibody response in the host. WHO's global strategy for further reducing the leprosy burden and sustaining leprosy control activities, in all endemic communities, could not be fulfilled in absence of potential diagnostic tools. The accurate diagnosis of leprosy is the urgent need of all aspects of leprosy control. Overdiagnosis will lead to unnecessary treatment and sentimental stigma of persons. Underdiagnosis will be a way allowing for spread of disease. The ideal diagnostic test should be able to detect all leprosy patients (100\% sensitivity) and indicate absence of $M$. leprae in healthy individuals (100\% specificity). The sensitivity and specificity can be determined by comparison with true negative and true positive obtained in another reliable, well-established (gold standard) test. Case of leprosy slit skin smear and histopathological test are considered to be reliable but due to many technical problems reliability of these tests could be affected. Thus these are not perfect tests [2-5]. The PGL-1 fraction is part of the cell envelope of $M$. leprae and induces the production of the specific humoral response against PGL-1 detected in patient serum [6-8]. Immunohistological test to stain PGL-1 antigen showed higher specificity than routine histopathology [9]. Further confirmation is sought by additional studies. The PGL-1 antibody assay in combination of skin lesion was found to have up to $77 \%$ sensitivity and $93 \%$ specificity in 
MB patients from Brazil [10]. In Nepal PGL-1 indicated 84\% sensitivity with very low specificity [11]. PGL-1 testing has been reported to be useful in MB relapse detection [12]. PGL1 IgM test in study among household contacts has proved importance of consanguinity for the development of antiPGL-1 IgM antibodies in most of the contacts with a family history of leprosy [13]. However, all household contacts did not show development of leprosy and a small group of patients remains who will be untreated. At present diagnosis of leprosy generally depends on dermatological sign alone and skin smear tests. The macules are the most apparent signs, but of low predictive value. Nevertheless, they are an early but nonspecific sign of leprosy and are often neglected by the patient or physicians. Other than macules, neurological (dysesthesia, motor disorders) signs may appear early on or be observed at a late stage in the progression of the disease [14]. Thus, newer serological tests based on protein antigen and or combination of protein antigen by combination of suitable IgM, IgG, or IgA may eventually overcome such difficulties.

\section{Antigens Applied for Serodiagnosis}

The antigenic analysis was hampered for M. leprae, as no one can be able to culture bacilli in artificial media for antigenic analysis. Investigators have used lepromatous nodules as a limited source of bacilli and identified unique $M$. leprae protein antigens that are not shared by other mycobacteria [15]. In 1968-1970 the armadillo (Dasypus novemcinctus) was identified as an animal model to study M. leprae. This animal was selected because of its long life span and lower body temperature $\left(30-35^{\circ} \mathrm{C}\right)[16,17]$. Later on leprosy was reported in wild armadillos in the Southern United States, suggesting an association between natural leprosy disease in humans and armadillos. In 1985, experimentally infected armadillos serum and whole blood were examined by Truman to detect antibodies against the $M$. leprae major antigens using enzyme-linked immunosorbent assay (ELISA) for immunoglobulin $\mathrm{M}$ (IgM) antibodies to the species-specific phenolic glycolipid-I (PGL-1) antigen. However, these antibodies have no protective effect against $M$. leprae and are usually associated with high false-positive rates within leprosy endemic regions [18]. It is after discovery of armadillo as experimental animal [16] to culture M. leprae. Better knowledge of the specific antigens responsible for immune responses in leprosy patients is useful to develop a peptide or DNA vaccine against leprosy and to identify selective serological diagnostic reagents, since studies based on sodium dodecyl sulphate polyacrylamide gel electrophoresis [19-23] to 2-dimensional gel electrophoresis [24-35] to define the proteome of $M$. leprae have proposed the existence of specific antigens in $M$. leprae that are located in cell membrane, cell wall, and cytosolic for their utility in the serodiagnosis.

Heat stable antigens $(12 \mathrm{kDa}, 22 \mathrm{kDa}, 28 \mathrm{kDa}, 36 \mathrm{kDa}$, $41 \mathrm{kDa}$, and $86 \mathrm{kDa}$ ) were identified from $M$. leprae sonicates on using SDS-PAGE and treatment of gel with peroxidaselabelled anti-human IgG [36]. The lepromatous patients were more reactive against the defined antigens. Patient-wise variation in reactivity towards these antigens was found within this group. Similar variations were found by other authors measuring antibody reactivity against $M$. leprae antigens [3740].

2.1. Whole M. leprae Sonicated Antigen. Whole M. leprae was used as an antigen [41] after removing cross-reactive component by absorbing the serum with cardiolipin, lecithin, BCG, and $M$. vaccae and employed in fluorescent leprosy antibody absorption (FLA-ABS) test. FLA-ABS test is being carried out in Japan, India, China, Korea, and many other countries of the Indian subcontinent. Most of the studies have showed $90 \%$ to $100 \%$ positivity in lepromatous and $70 \%$ to $80 \%$ in tuberculoid leprosy. Household healthy contacts of leprosy patients also showed $70 \%$ to $80 \%$ positivity indicating subclinical infection with $M$. leprae in the population.

2.2. $34 \mathrm{kDa}$ Protein. Gene ML0158 has a product of 314 amino acids and (31374 da) of Mycobacterium leprae protein (http:// www.sanger.ac.uk/Projects/M_leprae/CDS/ML0158.shtml). $34 \mathrm{kDa}$ cell wall antigen is isologous to the immunodominant 34-kilodalton antigen of $M$. paratuberculosis. And similarly, $34 \mathrm{kDa}$ isolog of $M$. leprae that also resides at the $\mathrm{C}$ terminus subcellular fractions of $M$. leprae provided unequivocal proof of the presence of two native versions of the $34 \mathrm{kDa}$ protein. The antigen has been found to be lacking significant serological activity [42].

2.3. $35 \mathrm{kDa}$ (MMP-1) Protein. It is a product of gene ML0841. Its 307 amino acid sequence has molecular weight of $33652 \mathrm{da}$. This protein can also be known as major membrane protein-I (http://www.sanger.ac.uk/Projects/M_leprae/CDS/ ML0841.shtml). $35 \mathrm{kDa}$ antigen of $M$. leprae was found in membrane fraction identified by Sinha et al. [43] and proved to be reactive to epitope on antibodies MAb ML04 in leprosy patient. This protein independently was identified by Hunter et al. [44] as a major membrane protein-I (MMPI). It shows strong $\mathrm{T}$-cell response in leprosy patients, elicits specific delayed type hypersensitivity, and stimulates IFN $\gamma$ production also. This protein is absent in $M$. bovis and $M$. tuberculosis. It has detected the fact that $90 \%$ lepromatous cases and $40 \%$ tuberculoid patients have been reported as positive by using this antigen [43]. It also shows a weak positive response to tuberculosis patients. It has homologues in M. intracellulare, M. avium, and M. paratuberculosis.

2.4. ESAT-6 Protein. ESAT-6 in M. leprae found as homologue protein expressed that appearance in cell wall fraction shows only $36 \%$ homology in comparison to tuberculosis ESAT-6 [45, 46]. The anti-M. leprae ESAT-6 polyclonal and monoclonal antibodies and T-cell hybridomas reacted only with the homologous proteins and allowed B- and T-cell epitopes. The $M$. leprae ESAT-6 shows promise as a specific diagnostic agent for leprosy [46]. There is also a probable secreted antigen, product of gene ML0050 having molecular weight of $10964 \mathrm{Da}$ and known as $10 \mathrm{kDa}$ protein. This protein is a member of ESAT- 6 protein and resembles culture 
filtrate protein-10 (CFP-10) of Mycobacterium tuberculosis (http://www.sanger.ac.uk/Projects/M_leprae/CDS/ML0050 .shtml).

2.5. $10 \mathrm{kDa}$ Protein. This is a product of gene groES ML0380. It has molecular weight of $10800 \mathrm{Da}$ with known one hundred amino acids (http://www.sanger.ac.uk/Projects/M_leprae/ CDS/ML0380.shtml). $10 \mathrm{kDa}$ heat shock protein found in cell wall fraction is an important antigen recognized by $\mathrm{T}$ cells, also known as chaperonin-10 (cpn-10). It responds to approximately $1 / 3$ rd of the $M$. leprae reactive T-cells in the patients with tuberculoid leprosy [47]. It elicits DTH response in $M$. leprae sensitized guinea pig. It lacks specificity as it shows $90 \%$ identity with its Mycobacterium tuberculosis counterpart. It has a flexible region, known to interact with cpn-60.

2.6. $15 \mathrm{kDa}$ Protein. It is a product of gene lsr2 ML0234 and has molecular weight of $12165 \mathrm{Da}$. There are one hundred and twelve amino acids found in this antigen. Homologues are present for this antigen in Streptomyces coelicolor (http://www.sanger.ac.uk/Projects/M_leprae/CDS/ML0234 .shtml). This $15 \mathrm{kDa}$ non-fusion protein from cell wall have shown strong reactivity with LL patients to screen mycobacterial $\lambda$ gt1l libraries. Antigen is also recognized by B-cell epitopes which recognize antibodies of patients from different geographical region. Antigen has property of clear recognition of human T-cells from leprosy patients $[48,49]$.

2.7. $18 \mathrm{kDa}$ Protein. Gene hsp18 ML1795 has a product of protein of molecular weight of $16707 \mathrm{Da}$ and a 148 amino acid sequence. The protein antigen is known as $18 \mathrm{kDa}$ heat shock protein (http://www.sanger.ac.uk/Projects/M_leprae/CDS/ ML1795.shtml). The M. leprae $18 \mathrm{kDa}$ provides $70 \%$ sensitivity among LL patients and about $72 \%$ among BT cases. It has been also found to be cross-reactive with sera from tuberculosis patients [50].

2.8. $21 \mathrm{kDa}$ Protein. This conserved hypothetical protein has molecular weight of $24521 \mathrm{Da}$ and contains about 228 amino acids. It is a product of gene ML2200 (http://www.sanger.ac.uk/Projects/M_leprae/CDS/ML2200.shtml). The $M$. leprae surface shows a marked protein (SDS predicted MW $28 \mathrm{kDa}$ ) for myelin producing Schwann cells; a surfaceexposed laminin binding protein (LBP) of molecular mass $21 \mathrm{kDa}$ (ML-LBP21) (found after peptide sequencing) may be an important virulence factor. Recombinant ML-LBP21 shows response against monoclonal antibodies [51, 52]. Rambukkana et al. [53] described how the G-domain of the laminin- $\alpha_{2}$ chain in the basal lamina that surrounds the Schwann cell axon unit serves as an initial neural target for $M$. leprae. By using human- $\alpha_{2}$ laminin as probe, a major $28 \mathrm{kDa}$ protein in the $M$. leprae cell wall fraction was identified. The $28 \mathrm{kDa}$ protein functions as critical surface adhesive that facilitates the entry of $M$. leprae in Schwann cells. Pessolani and Brennan [29] had also described a similar $28 \mathrm{kDa}$ protein as a key bacterial ligand in $M$. leprae Schwann cells interaction and have shown that it is a member of histone like protein family.

2.9. $30 \mathrm{kDa}$ Protein. This is also a conserved hypothetical protein. It is product of gene ML0849 having 283 amino acids. The molecular weight of this protein is about $30520 \mathrm{da}$ (http://www.sanger.ac.uk/Projects/M_leprae/CDS/ML0849 .shtml). The M. leprae $30 / 31 \mathrm{kDa}$ protein is only known as a secreted protein that induces strong humoral and cellular immune response and it contains at least two fibronectin binding sites. This $30 / 31 \mathrm{kDa}$ protein not only is important in the immune response against $M$. leprae but may also have a biological role in the interaction of this bacillus with the human host [54].

2.10. $45 \mathrm{kDa}$ Protein. This is a product of gene ML0411 having molecular weight of about $42467 \mathrm{da}$. And it contains approximate four hundred and eight known amino acids (http://www.sanger.ac.uk/Projects/M_leprae/CDS/ML0411 .shtml). The $45 \mathrm{kDa}$ protein (antigen) found in the $M$. leprae sonicate shows that human T-cell response reflects infection with or exposure to M. leprae. It is a serine rich antigen found to give peripheral blood mononuclear cell proliferation response about $92.8 \%$ in tuberculoid leprosy cases, in lepromatous leprosy cases it was $60.6 \%$, in leprosy contacts it was $88 \%$, and in controls it was $10 \%$ [55]. Parkash et al. [56] have evaluated this antigen for $\mathrm{MB}$ and $\mathrm{PB}$ cases and found this serine rich molecule as highly specific for leprosy. There were about $94.4 \% \mathrm{MB}$ and $36.8 \% \mathrm{~PB}$ found to be positive on using molecule as diagnostic tool.

2.11. MMP-II (Bfr) Protein. This antigen corresponds to gene bfrA ML2038 or pseudogene bfrB ML0075 (http:// www.sanger.ac.uk/Projects/M_leprae/CDS/ML0075.shtml) and there are one hundred and fifty-nine amino acids known for bfrA ML2038 with a molecular weight of $18263 \mathrm{da}$ (http://www.sanger.ac.uk/Projects/M_leprae/CDS/ML2038 .shtml ). Bacterioferritin (Bfr) is a major membrane protein II (MMP-II) observed abundantly in in vivo grown $M$. leprae involved in acquisition and storage of iron. In the context of Johne's disease, M. paratuberculosis Bfr is an immunodominant B-cell antigen, and it is the key component of a diagnostic test [57]. Therefore relevance of $M$. leprae Bfr as an antigen for the purpose of diagnosis can be explored.

2.12. TR/Trx Protein. This protein is a gene product of gene trxB ML2703 and its molecular weight is 49047 da. The protein has 458 amino acids (http://www.sanger.ac .uk/Projects/M_leprae/CDS/ML2703.shtml). This bifunctional hybrid protein thioredoxin/thioredoxin reductase (TR/Trx) found only in M. leprae among Mycobacteria as TR and TRX are separate proteins in other Mycobacteria. The N terminus of it is homologous to the TR and C terminus to Trx. This protein is active by itself and its activity involves intramolecular interaction between TR and Trx domains. This protein also shows the intramolecular interaction in excess of TR or Trx [58]. The diagnostic role of the antigen 
seems to be absent as other bacteria have protein but only in form of two separate molecules.

2.13. $65 \mathrm{kDa}$ Protein. There is a $65 \mathrm{kDa}$ protein found in both membrane and cytosol of $M$. leprae [59]. It is Chepronin $65 \mathrm{kDa}$ GroEL-2 related to the family of heat shock proteins which is the major protein present in host derived $M$. leprae [44]. There are only $29 \%$ leprosy patients responding to it.

2.14. Ahpc Protein. Ahpc protein of M. leprae shows similarity with the C22 unit of alkyl hydroperoxide reductase (Ahpc) from Salmonella typhimurium, a detoxifying enzyme that reduces organic hydroperoxides to their corresponding alcohols. Homologous M. leprae AhpC protein is a member of the AhpC-thiol specific family of enzymes with antioxidant activities. This protein plays a key role in the survival of $M$. leprae in the midst of high concentration of oxygen-reactive species produced by macrophages [29].

2.15. CysA Protein. There is a protein for cysteine biosynthesis and sulfur assimilation in M. leprae that is known as CysA protein. The gene for this also encodes a putative sulfate sulfurtransferase enzyme. But it shows high similarity to Saccharopolyspora erythraea CysA and both of them show homology to human liver protein rhodanese [29].

\section{Recombinant Proteins in Diagnosis of Leprosy}

Based on $M$. leprae cDNA library screening results [21] thirty-three protein antigens were ML0022, ML0051, ML0098, ML0176, ML0276, ML0393, ML0405, ML0489, ML0491, ML0540, ML0810, ML0811, ML0840, ML1383, ML1556, ML1632, ML1181, ML1481, ML1633, ML1685, ML2028, ML2044, ML2055, ML2203, ML2331, ML2346, ML2358, ML2380, ML2541, ML2603, ML2629, ML2655, and ML2659; recombinant proteins were studied for immune response [60]. Of these, ML0405, ML2055, and ML2331 were incubated with blood from TT/BT and healthy household contacts (of LL/BL patients) groups; the proteins induced strong IFN $\gamma$ production but weak or absent antibody responses, although ML0405 and ML2331 proteins were well recognized by serum IgG from LL/BL leprosy group [60]. Researchers suggested that the antibody response to $M$. leprae recombinant proteins was dependent upon their ability to induce cellular responses and indicates that only a limited number of $M$. leprae antigens contained T-cell and B-cell epitopes that are immune reactive in the context of disease (ML0405, ML2055, and ML2331). Sampio et al. [60] suggested a combination of whole blood assay prior to serological assays for beneficial protein screening. Most of these antigens neither induced IFN $\gamma$ secretion nor showed IgG reactivity. The antigens showing IgG reactivity can be a potential combination with PGL-1 antigen for leprosy diagnosis.

\section{Peptide Based Serodiagnosis}

It is hypothesised that during dormancy of disease most patients are subclinically infected and this subclinical infection could be source of $M$. leprae transmission. The modern tools and improved bioinformatics to study genome sequence of $M$. leprae have opened new door of possibilities for leprosy research. Now we are positioned to predict more relevant $M$. leprae proteins and potential human leukocyte antigen (HLA) class I and class II epitopes that can activate T-cells [61]. These postgenomic approaches have proposed novel $M$. leprae protein or peptide-specific T-cell responses to identify $M$. leprae-exposed or M. leprae-infected individuals [19, 20, 26, 62-64].

Antigenic proteins typically contain multiple peptide epitopes. Comparably, antigenic proteins have better diagnostic potential due to reduced or absent T-cell crossreactivity [26] and [65]. Analysis of $M$. leprae peptides or pools of peptides in geographically different endemic regions could provide unique 138,938 20-mer peptide sequences derived from 1,546 different $M$. leprae candidate proteins. To reduce the number of candidate peptides for BLAST, Bobosha et al. [66] proposed selected peptides derived from genes in the functional classification group IV.A (virulence) (including the following 13 genes: ML0360, ML0361, ML0362, ML0885, ML1214, ML1358, ML1811, ML1812, ML2055, ML2208, ML2466, ML2589, and ML2711) (http://www.sanger.ac.uk/Projects/M_leprae/Ml_gene_list_ hierarchical.shtml, currently designated as "genes involved in virulence, detoxification and adaptation" or "genes involved in cell wall and cell processes" on http://mycobrowser.epfl .ch/leprosy.html). These peptides induced T-cell reactivity in leprosy patients or healthy individuals living in regions. The potential diagnostic reagents were predominantly derived from ML1601, ML2055, ML1358, and ML1214. There was region-wise variation in response to these peptides. The discrepancy among peptide's responses could be due to variation in HLA polymorphism; however, peptides have potential use in estimating the level of $M$. leprae exposure [66]. ML2055 has also been reported to induce strong serological responses in lepromatous patients [60]. The immune response against $M$. leprae infection is a collective/synergistic response of various immune cascades that involve the induction of both cytokines and chemokines by innate and adaptive immune cells [66]. The main advantage arising from the use of synthetic peptides compared with the use of proteins is that peptides less frequently induce T-cell cross-reactivity [20] However, because of the HLA-restriction of peptides that are recognised by T-cells, single peptides are not able to cover diverse populations.

\section{Recent In-House Studies towards Leprosy Diagnosis}

Most of these protein antigens have been reported to induce T-cell response from tuberculoid leprosy patients and their contacts in vitro. However, majority of these antigens have 
been shown to be cross-reactive with homologues identified in other mycobacterial species. Hence, such antigens would not be useful as diagnostic reagents.

In the past decade, clinically defined leprosy patients were analyzed by us for BI indices, MLF test, and indirect ELISA. Sera from healthy individuals working in various laboratories of the institute were tested for defining cut-off value. Whole $M$. leprae sonicate antigen was recognized by leprosy patient sera (Figure 1); equal or more than a cut-off (calculated by mean optical density +2 standard deviation for healthy controls) was considered to have acceptable antibodies titer (Figure 1). Sera from selected LL with BI positive (MB) and $\mathrm{BT}$ with $\mathrm{BI}$ negative $(\mathrm{PB})$ leprosy were tested in triplicate, and the mean absorbance for control wells without antigen was subtracted from that for sample wells before analysis. Twodimensional gel electrophoresis (2DE) separated proteins of $M$. leprae (cytosol, cell wall, and cell membrane) were immunoblotted with anti-human IgA/IgM/IgG to obtain immunoblots against sera of leprosy patients, tuberculosis patients, and healthy individuals. The observed immunogenic antigen of $M$. leprae present specifically only in leprosy sera would then be recognized and analysed statistically.

\subsection{Estimation of Antibody Titers, in Sera Samples, against} Whole M. leprae Protein Antigens. The M. leprae flow(MLF) test and bacterial index (BI) (slit skin smear) of patients were used to select samples to calculate higher antibody titer to identify potential protein antigens that could ultimately serve as the basis for an immunodiagnostic test for leprosy. To check the potential specificity of MLSA, MLMA, and MLCwA, we selected serum samples with appropriate antibody titer which was given by indirect ELISA. Initially, sera samples were collected and classified as LL/BL and BT [67]. However, since they were clinically leprosy patients, serological analysis was performed with the MLF test and indirect ELISA which gave us a set of serum samples of leprosy patients that were likely to be strictly having higher load of antibodies against M. leprae.

5.2. Selection of Serum Samples Having Applicable Anti-M. leprae Antibody Titer. Leprosy patients were classified as multibacillary $(\mathrm{MB})$ and paucibacillary $(\mathrm{PB})$ on the basis of clinical criteria given in guidelines of WHO and NLEP [68]. Briefly, patients with more than 5 lesions and/or 2 or more affected nerve trunks were classified as $\mathrm{MB}$ (23LL/2BL/4BB/41BT/14N). Patients with up to 5 lesions with or without nerve thickenings $(<2)$ were included in $\mathrm{PB}$ group $(13 \mathrm{BT} / 1 \mathrm{I} / 3 \mathrm{~N})$. All selected LL patients had bacilli in the skin smear and were positive with MLF whereas BT patients were negative for both. $92.0 \%$ of the MB patients and $32.0 \%$ of $\mathrm{PB}$ patients were serologically positive by the ML Flow test [69]. In- house calculated cut-off values regarding $\operatorname{IgA}$, IgM, and IgG were $0.206,0.325$, and 0.5 , respectively.

5.3. Analysis of ELISA and Immunoblot Observations. Indirect ELISA for calculating antibodies level for whole $M$. leprae sonicated antigen (WMLS) in serum samples where we have found serological positivity of 10/22 (45.45\%), 9/35 (25.71\%),
TABLE 1: The number of proteins (antigens) reactive to various sera samples of leprosy patients which were not presented by healthy people's and tuberculosis patients' sera.

\begin{tabular}{lcccc}
\hline Groups & IgG & IgA & IgM & Total \\
\hline Cytosolic proteins (MLSA) & 11 & 04 & 03 & 18 \\
Cell wall proteins (MLCwA) & 04 & 01 & 02 & 07 \\
Cell membrane proteins (MLMA) & 03 & 06 & 05 & 14 \\
\hline Total leprosy patients' sera reactive spots & 18 & 11 & 10 & 39 \\
\hline
\end{tabular}

and 15/32 (46.88\%) in leprosy cases with anti-IgA, IgG, and IgM was taken as detector antibody in leprosy patients, respectively. Indirect ELISA for calculating antibodies level for whole $M$. leprae sonicated antigen (WMLS) in serum samples where OD values have cut-off values $(0.206,0.5$, and 0.325 ) (Figure 2) at dilution $1: 1600,1: 400$, and $1: 800$ of serum, respectively, with anti-IgA, IgG, and IgM was taken as detector antibody in untreated leprosy patients, respectively. Immunoblot of cytosolic $M$. leprae fractions had majority of antigens (18/39 spots, Table 1). Of these, major numbers 11/18 spots were paired with IgG antibodies in sera (4 with antiIgA and 3 with anti-IgM). On further analysis, majority of antigens from cytosol and cell wall raised IgG antibody titer while cell membrane has major number of antigens to raise IgA antibodies. Most of antigens of $M$. leprae responsible to raise IgM titer were also located in cell membrane. The samples were collected from patients and healthy individuals who are resident in India where people are supposed to be immunized at the age of 6 weeks with BCG. That is why very few of these antigen spots were found as specific to leprosy in study. Hence, immunoblot based leprosy specific antigens were identified by using MALDI-TOF/TOF.

Our assays (based on IgG, IgA, and IgM) indicated that lepromatous leprosy patients have higher antibody titer in comparison to BT patients. Therefore the study was focused towards investigating the best immunoglobulin and antigen combination to diagnose higher number of BT patients. All proteins of $M$. leprae would not react in similar fashion in all individuals and they rely on the patient's immunity. On considering immunoglobulins, IgG responded against more numbers of antigens (18) than IgA (11) or IgM (10). Among these, MALDI TOF/TOF based leprosy specific antigenic repertoires of only 8 proteins were found to belong to membrane fraction [70]. Reported antigen MAL5 was recognized with IgA having $82.6 \%$ sensitivity with maintaining specificity up to $54.5 \%$ which is the best among all these specific antigens. MALDI-TOF-MS/MS of MAL5 indicated it as MMP-I. After considering immunoblot and MALDI results MAL5 is an isoform of MMPI [70]. Immunoblot based leprosy specific antigens (in comparison to Mycobacterium tuberculosis) were not supposed to be potential diagnostic reagent if they were not specific to $M$. leprae in MALDITOF/TOF observations (found homologous with other actinomycetes) (unpublished data).

Therefore study suggested that if one has chosen cell membrane protein for leprosy diagnosis, then IgA will be a better detector antibody. Further searching peptide in these antigens can provide better diagnostic tool when IgA will 


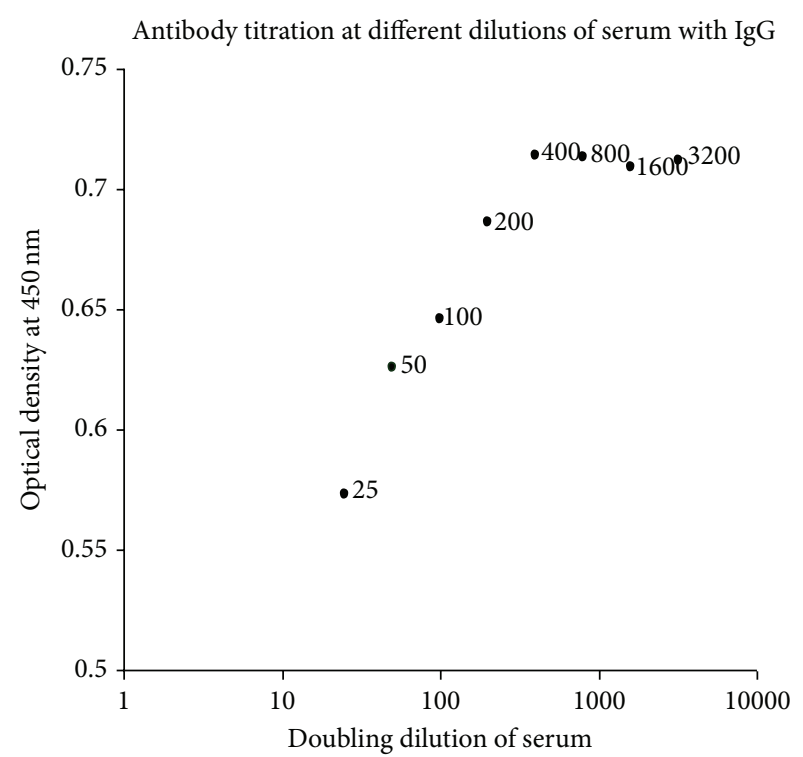

(a)

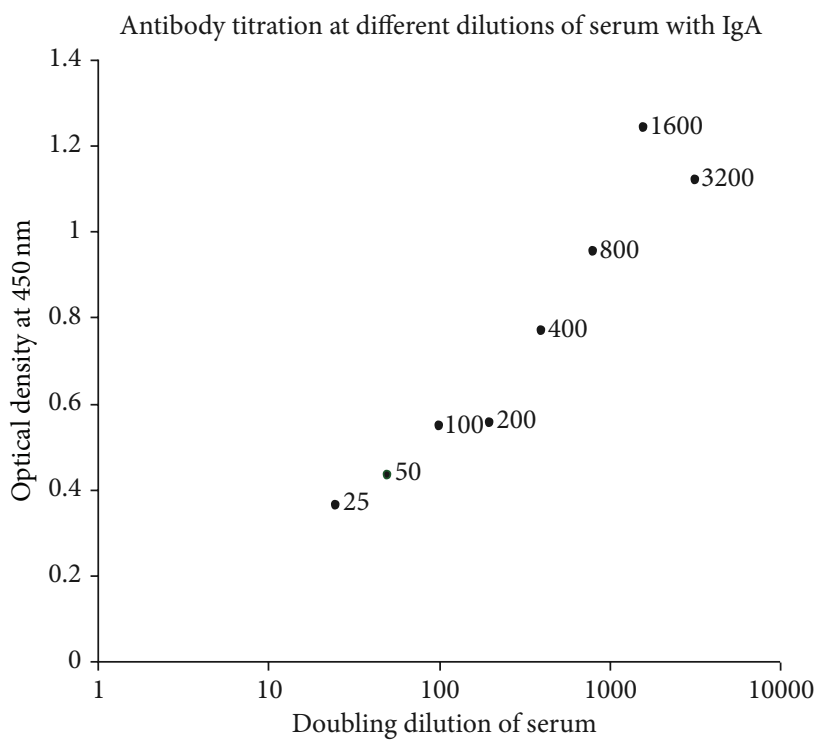

(b)

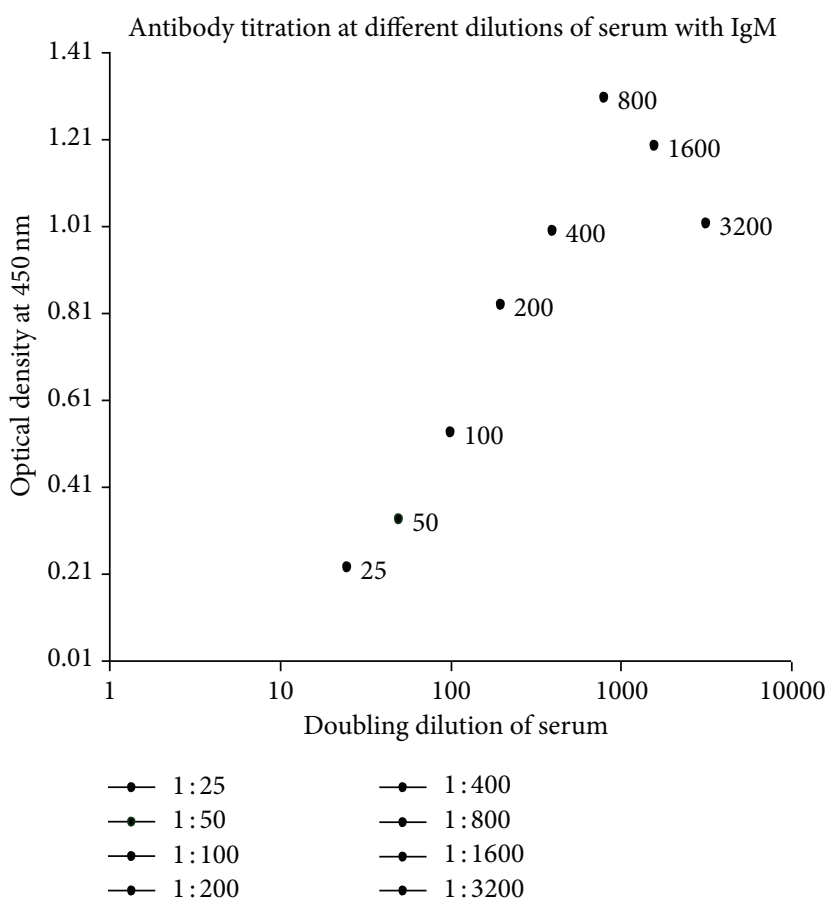

(c)

FIGURE 1: Bacterial index (BI) and MLF positive serum samples were used for calculating the best dilution of serum to recognize samples having anti-M. leprae antibodies. Results indicated that $M$. leprae infected human serum was reacted with the whole $M$. leprae sonicated antigen proteins where detector antibody was (a) IgG, (b) IgA, or (c) IgM. Examination of sera gives a general pattern found as above. Thus selected dilution of serum was 1:400 1:800 and 1:1600 for immunoblots with IgG, IgM, and IgA, respectively.

be a detector antibody. The $M$. leprae had wide number of antigens which were cross-reactive to other bacteria. Among 39 investigated antigens for diagnosis purpose, antigen MAL5, recognized with IgA, having $82.6 \%$ sensitivity with maintaining specificity up to $54.5 \%$, is the best among all above mentioned antigens. This study has also opened a door of hope to search a protein (peptide) to develop vaccine to prevent leprosy.

\section{Future of Leprosy Serodiagnosis}

Hungria et al. [71] investigated serologic reactivity to the novel M. leprae proteins $46 \mathrm{f}$ and $92 \mathrm{f}$,"leprosyIDRI diagnostic1" (LID-1), and ML0405 and ML1213 using IgG as detection antibody and suggested that enrichment of PGL-1 + IgM test with any of these antigens + IgG could improve serodiagnosis of leprosy cases. 


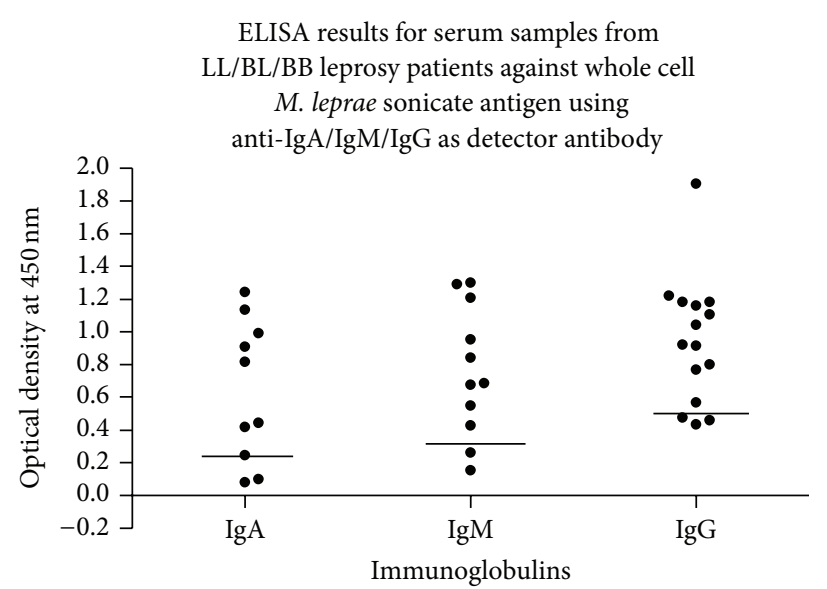

(a)

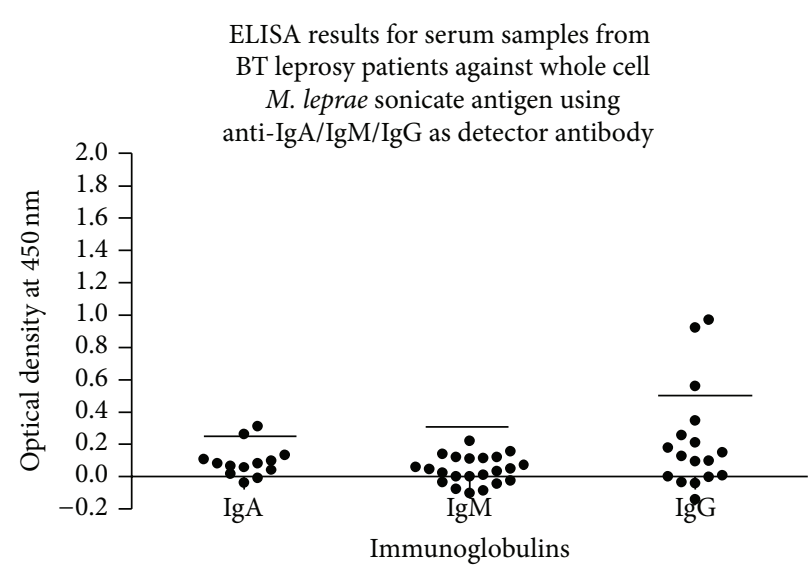

(b)

FIGURE 2: Leprosy patients responses to IgG, IgA, and IgM above cut-off values were selected as positives. Here anti-IgA/IgM/IgG was taken as detector antibody for (a) LL/BL/BB and (b) BT leprosy patient.

Similarly, peptides from these and above-mentioned proteins can provide specific immune responses in leprosy patients in an endemic region. Thus synergistic combination of proteins/protein, protein-PGL-1, or peptide could be useful to develop a rapid diagnostic test for the early detection of $M$. leprae infection and epidemiological surveys of the incidence of leprosy, of which little is known. Still in all these sets one has to know the most suitable detector antibody. Studies have suggested that IgG makes combination with larger number of $M$. leprae proteins for diagnosis but so far tested antigens could not be able to provide high specificity. Considering above-mentioned antigens and in-house study, M. leprae had higher number of specific antigens in cell membrane if visualized in immunoblots using IgA and IgM as detector antibodies.

\section{Conclusion}

Immunoblot and ELISA based study of $M$. leprae antigens can suggest highly specific and sensitive protein molecules from endemic region of leprosy that can be used as diagnostic reagent if proper immunoglobulin was a detector antibody. We can also develop a peptide based on synergistic combination for serodiagnostic test to identify presence of $M$. leprae in the patient's body.

\section{Conflict of Interests}

The authors declare that there is no conflict of interests regarding the publication of this paper.

\section{Acknowledgments}

The authors are thankful to CSIR and ICMR for funds provided during research activities in laboratory.

\section{References}

[1] R. W. Truman and J. L. Krahenbuhl, "Viable M. leprae as a research reagent," International Journal of Leprosy and Other Mycobacterial Diseases, vol. 69, no. 1, pp. 1-12, 2001.

[2] I. A. Cree, T. Srinivasan, S. A. Krishnan et al., "Reproducibility of histology in leprosy lesions," International Journal of Leprosy and Other Mycobacterial Diseases, vol. 56, no. 2, pp. 296-301, 1988.

[3] R. Nilsen, G. Mengistu, and B. B. Reddy, "The role of nerve biopsies in the diagnosis and management of leprosy," Leprosy Review, vol. 60, no. 1, pp. 28-32, 1989.

[4] B. Kumar and S. Dogra, "Leprosy: a disease with diagnostic and management challenges!, Indian Journal of Dermatology, Venereology and Leprology, vol. 75, no. 2, pp. 111-115, 2009.

[5] G. D. Georgiev and A. C. McDougall, "Skin smears and the bacterial index (B) in multiple drug therapy leprosy control programs: an unsatisfactory and potentially hazardous state of affairs," International Journal of Leprosy and Other Mycobacterial Diseases, vol. 56, no. 1, pp. 101-104, 1988.

[6] N. T. Foss, F. Callera, and F. L. Alberto, "Anti-PGL1 levels in leprosy patients and their contacts," Brazilian Journal of Medical and Biological Research, vol. 26, no. 1, pp. 43-51, 1993.

[7] S. N. Cho, D. L. Yanagihara, S. W. Hunter, R. H. Gelber, and P. J. Brennan, "Serological specificity of phenolic glycolipid I from Mycobacterium leprae and use in serodiagnosis of leprosy," Infection and Immunity, vol. 41, no. 3, pp. 1077-1083, 1983.

[8] S. W. Hunter, T. Fujiwara, and P. J. Brennan, "Structure and antigenicity of the major specific glycolipid antigen of Mycobacterium leprae," Journal of Biological Chemistry, vol. 257, no. 24, pp. 15072-15078, 1982.

[9] X.-M. Weng, S.-Y. Chen, S.-P. Ran et al., "Immunohistopathology in the diagnosis of early leprosy," International Journal of Leprosy and Other Mycobacterial Diseases, vol. 68, no. 4, pp. 426-433, 2000.

[10] S. Buhrer-Sekula, E. N. Sarno, L. Oskam et al., "Use of ML dipstick as a tool to classify leprosy patients," International Journal of Leprosy and Other Mycobacterial Diseases, vol. 68, no. 4, pp. 456-463, 2000. 
[11] J. W. LeMaster, T. Shwe, C. R. Butlin, and P. W. Roche, "Prediction of "highly skin smear positive" cases among MB leprosy patients using clinical parameters," Leprosy Review, vol. 72, no. 1, pp. 23-28, 2001.

[12] R. A. Chin-A-Lein, W. R. Faber, M. M. van Rens, D. L. Leiker, B. Naafs, and P. R. Klatser, "Follow-up of multibacillary leprosy patients using a phenolic glycolipid-I-based ELISA. Do increasing ELISA-values after discontinuation of treatment indicate relapse?" Leprosy Review, vol. 63, no. 1, pp. 21-27, 1992.

[13] R. Bazan-Furini, A. C. F. Motta, J. C. L. Simão et al., "Early detection of leprosy by examination of household contacts, determination of serum anti-PGL-1 antibodies and consanguinity," Memórias do Instituto Oswaldo Cruz, vol. 106, no. 5, pp. 536-540, 2011.

[14] S. Keita, A. Tiendrebeogo, D. Berthe, O. Faye, and H. T. N’Diaye, "Predictive value of medical reasons in the diagnosis of leprosy in Bamako (Mali)," Annales de Dermatologie et de Venereologie, vol. 129, no. 8-9, pp. 1009-1011, 2002.

[15] H. D. Caldwell, W. F. Kirchheimer, and T. M. Buchanan, "Identification of a Mycobacterium leprae specific protein antigen(s) and its possible application for the serodiagnosis of leprosy," International Journal of Leprosy, vol. 47, no. 3, pp. 477-483, 1979.

[16] W. F. Kirchheimer and E. E. Storrs, "Attempts to establish the armadillo (Dasypus novemcinctus Linn.) as a model for the study of leprosy. I. Report of lepromatoid leprosy in an experimentally infected armadillo.", International Journal of Leprosy and Other Mycobacterial Diseases, vol. 39, no. 3, pp. 693702, 1971.

[17] W. F. Kirchheimer, E. E. Storrs, and C. H. Binford, "Attempts to establish the armadillo (Dasypus novemcinctus Linn.) as a model for the study of leprosy. II. Histopathologic and bacteriologic post mortem findings in lepromatoid leprosy in the armadillo," International Journal of Leprosy, vol. 40, no. 3, pp. 229-242, 1972.

[18] R. W. Truman, M. J. Morales, E. J. Shannon, and R. C. Hastings, "Evaluation of monitoring antibodies to PGL-I in armadillos experimentally infected with M. leprae," International Journal of Leprosy and Other Mycobacterial Diseases, vol. 54, no. 4, pp. 556-559, 1986.

[19] A. Geluk, M. R. Klein, K. L. Franken et al., "Postgenomic approach to identify novel Mycobacterium leprae antigens with potential to improve immunodiagnosis of infection," Infection and Immunity, vol. 73, no. 9, pp. 5636-5644, 2005.

[20] J. S. Spencer, H. M. Dockrell, and H. J. Kim, "Identification of specific proteins and peptides in Mycobacterium leprae for the selective diagnosis of leprosy," Journal of Immunology, vol. 175, no. 12, pp. 7930-7938, 2005.

[21] S. T. Reece, G. Ireton, R. Mohamath et al., "ML0405 and ML2331 are antigens of Mycobacterium leprae with potential for diagnosis of leprosy," Clinical and Vaccine Immunology, vol. 13, no. 3, pp. 333-340, 2006.

[22] N. A. Groathouse, A. Amin, M. A. M. Marques et al., "Use of protein microarrays to define the humoral immune response in leprosy patients and identification of disease-state-specific antigenic profiles," Infection and Immunity, vol. 74, no. 11, pp. 6458-6466, 2006.

[23] M. S. Duthie, W. Goto, G. C. Ireton et al., "Use of protein antigens for early serological diagnosis of leprosy," Clinical and Vaccine Immunology, vol. 14, no. 11, pp. 1400-1408, 2007.

[24] M. S. Duthie, G. C. Ireton, G. V. Kanaujia et al., "Selection of antigens and development of prototype tests for point-of-care leprosy diagnosis," Clinical and Vaccine Immunology, vol. 15, no. 10, pp. 1590-1597, 2008.

[25] M. S. Duthie, W. Goto, G. C. Ireton et al., "Antigen-specific T-cell responses of leprosy patients," Clinical and Vaccine Immunology, vol. 15, no. 11, pp. 1659-1665, 2008.

[26] A. Geluk, J. S. Spencer, K. Bobosha et al., "From genome-based in silico predictions to ex vivo verification of leprosy diagnosis," Clinical and Vaccine Immunology, vol. 16, no. 3, pp. 352-359, 2009.

[27] J. S. Spencer, H. J. Kim, W. H. Wheat et al., "Analysis of antibody responses to Mycobacterium leprae phenolic glycolipid I, lipoarabinomannan, and recombinant proteins to define disease subtype-specific antigenic profiles in leprosy," Clinical and Vaccine Immunology, vol. 18, no. 2, pp. 260-267, 2011.

[28] M. S. Duthie, M. N. Hay, C. Z. Morales et al., "Rational design and evaluation of a multiepitope chimeric fusion protein with the potential for leprosy diagnosis," Clinical and Vaccine Immunology, vol. 17, no. 2, pp. 298-303, 2010.

[29] M. C. Pessolani and P. J. Brennan, "Molecular definition and identification of new proteins of Mycobacterium leprae," Infection and Immunity, vol. 64, no. 12, pp. 5425-5427, 1996.

[30] M. A. M. Marques, S. Chitale, P. J. Brennan, and M. C. Pessolani, "Mapping and identification of the major cell wall-associated components of Mycobacterium leprae," Infection and Immunity, vol. 66, no. 6, pp. 2625-2631, 1998.

[31] M. A. M. Marques, B. J. Espinosa, E. K. X. da Silveira et al., "Continued proteomic analysis of Mycobacterium leprae subcellular fractions," Proteomics, vol. 4, no. 10, pp. 2942-2953, 2004.

[32] M. A. M. Marques, A. G. C. Neves-Ferreira, E. K. X. da Silveira et al., "Deciphering the proteomic profile of Mycobacterium leprae cell envelope," Proteomics, vol. 8, no. 12, pp. 2477-2491, 2008.

[33] G. A. de Souza, T. Søfteland, C. J. Koehler, B. Thiede, and H. G. Wiker, "Validating divergent ORF annotation of the Mycobacterium leprae genome through a full translation data set and peptide identification by tandem mass spectrometry," Proteomics, vol. 9, no. 12, pp. 3233-3243, 2009.

[34] H. G. Wiker, G. G. Tomazella, and G. A. de Souza, "A quantitative view on Mycobacterium leprae antigens by proteomics," Journal of Proteomics, vol. 74, no. 9, pp. 1711-1719, 2011.

[35] A. Kumar, B. K. Girdhar, and O. Parkash, "Seroreactivity of cytosolic proteins of Mycobacterium leprae separated by two dimensional gel electrophoresis and immunoblotting," Journal of Immunology and Immunopathology, vol. 8, no. 2, pp. 163-164, 2006.

[36] P. R. Klatser, M. M. Van Rens, and T. A. Eggelte, "Immunochemical characterization of Mycobacterium leprae antigens by the SDS-polyacrylamide gel electrophoresis immunoperoxidase technique (SGIP) using patients' sera," Clinical and Experimental Immunology, vol. 56, no. 3, pp. 537-544, 1984.

[37] R. Melsom, B. Naafs, M. Harboe, and O. Closs, "Antibody activity against Mycobacterium leprae antigen 7 during the first year of DDS treatment in lepromatous (BL-LL) leprosy," Leprosy Review, vol. 49, no. 1, pp. 17-29, 1978.

[38] R. Melsom, M. Harboe, B. Myrvang, T. Godal, and A. Belehu, "Immunoglobulin class specific antibodies to Mycobacterium leprae in leprosy patients, including the indeterminate group and healthy contacts as a step in the development of methods for serodiagnosis of leprosy," Clinical \& Experimental Immunology, vol. 47, no. 2, pp. 225-233, 1982.

[39] L. Yoder, B. Naafs, M. Harboe, and G. Bjune, "Antibody activity against Mycobacterium leprae antigen 7 in leprosy: studies on 
variation in antibody content throughout the spectrum and on the effect of DDS treatment and relapse in BT leprosy," Leprosy Review, vol. 50, no. 2, pp. 113-121, 1979.

[40] S. J. Brett, P. Draper, S. N. Payne, and R. J. W. Rees, "Serological activity of a characteristic phenolic glycolipid from Mycobacterium leprae in sera from patients with leprosy and tuberculosis," Clinical and Experimental Immunology, vol. 52, no. 2, pp. 271-279, 1983.

[41] M. Abe, F. Minagawa, Y. Yoshino, T. Ozawa, K. Saikawa, and T. Saito, "Fluorescent leprosy antibody absorption (FLA-ABS) test for detecting subclinical infection with Mycobacterium leprae," International Journal of Leprosy, vol. 48, no. 2, pp. 109-119, 1980.

[42] F. S. Silbaq, S. N. Cho, S. T. Cole, and P. J. Brennan, "Characterization of a 34-kilodalton protein of Mycobacterium leprae that is isologous to the immunodominant 34-kilodalton antigen of Mycobacterium paratuberculosis," Infection and Immunity, vol. 66, no. 11, pp. 5576-5579, 1998.

[43] S. Sinha, U. Sengupta, G. Ramu, and J. Ivanyi, "A serological test for leprosy based on competitive inhibition of monoclonal antibody binding to the MY2a determinant of Mycobacterium leprae," Transactions of the Royal Society of Tropical Medicine and Hygiene, vol. 77, no. 6, pp. 869-871, 1983.

[44] S. W. Hunter, B. Rivoire, V. Mehra, B. R. Bloom, and P. J. Brennan, "The major native proteins of the leprosy bacillus," The Journal of Biological Chemistry, vol. 265, no. 24, pp. 1406514068, 1990.

[45] K. Eiglmeier, N. Honore, S. A. Woods, B. Caudron, and S. T. Cole, "Use of an ordered cosmid library to deduce the genomic organization of Mycobacterium leprae," Molecular Microbiology, vol. 7, no. 2, pp. 197-206, 1993.

[46] J. S. Spencer, M. A. M. Marques, M. C. B. S. Lima et al., "Antigenic specificity of the Mycobacterium leprae homologue of ESAT-6," Infection and Immunity, vol. 70, no. 2, pp. 1010-1013, 2002.

[47] V. Mehra, B. Bloom, A. C. Bajardi et al., "A major T cell antigen of Mycobacterium leprae is a $10-\mathrm{kD}$ heat-shock cognate protein," Journal of Experimental Medicine, vol. 175, no. 1, pp. 275-284, 1992.

[48] S. Laal, Y. D. Sharma, H. K. Prasad et al., "Recombinant fusion protein identified by lepromatous sera mimics native Mycobacterium leprae in T-cell responses across the leprosy spectrum," Proceedings of the National Academy of Sciences of the United States of America, vol. 88, no. 3, pp. 1054-1058, 1991.

[49] S. Sela, J. E. R. Thole, T. H. M. Ottenhoff, and J. E. ClarkCurtiss, "Identification of Mycobacterium leprae antigens from a cosmid library: characterization of a 15-kilodalton antigen that is recognized by both the humoral and cellular immune systems in leprosy patients," Infection and Immunity, vol. 59, no. 11, pp. 4117-4124, 1991.

[50] T. Vikerfors, P. Olcén, H. Wiker, and J. D. Watson, "Serological response in leprosy and tuberculosis patients to the $18-\mathrm{kDa}$ antigen of Mycobacterium leprae and antigen 85B of Mycobacteriumbovis BCG," International Journal of Leprosy, vol. 61, no. 4, pp. 571-580, 1993.

[51] Y. Shimoji, N. G. Vincent, K. Matsumura, V. A. Fischetti, and A. Rambukkana, "A 21-kDa surface protein of Mycobacterium leprae binds peripheral nerve laminin-2 and mediates Schwann cell invasion," Proceedings of the National Academy of Sciences of the United States of America, vol. 96, no. 17, pp. 9857-9862, 1999.

[52] A. Rambukkana, H. Yamada, G. Zanazzi et al., "Role of $\alpha$ dystroglycan as a Schwann cell receptor for Mycobacterium leprae," Science, vol. 282, no. 5396, pp. 2076-2079, 1998.
[53] A. Rambukkana, J. L. Salzer, P. D. Yurchenco, and E. I. Tuomanen, "Neural targeting of Mycobacterium leprae mediated by the G domain of the laminin- $\alpha 2$ chain," Cell, vol. 88 , no. 6, pp. 811821, 1997.

[54] J. E. R. Thole, R. Schöningh, A. A. M. Janson et al., "Molecular and immunological analysis of a fibronectin-binding protein antigen secreted by Mycobacterium leprae," Molecular Microbiology, vol. 6, no. 2, pp. 153-163, 1992.

[55] A. Macfarlane, R. Mondragon-Gonzalez, F. Vega-Lopez et al., "Presence of human T-cell responses to the Mycobacterium leprae 45-kilodalton antigen reflects infection with or exposure to M. leprae," Clinical and Diagnostic Laboratory Immunology, vol. 8, no. 3, pp. 604-611, 2001.

[56] O. Parkash, R. Pandey, and A. Kumar, "Performance of recombinant ESAT-6 antigen (ML0049) for detection of leprosy patients," Letters in Applied Microbiology, vol. 44, no. 5, pp. 524530, 2007.

[57] M. C. V. Pessolani, D. R. Smith, B. Rivoire et al., "Purification, characterization, gene sequence, and significance of a bacterioferritin from Mycobacterium leprae," Journal of Experimental Medicine, vol. 180, no. 1, pp. 319-327, 1994.

[58] B. Wieles, J. van Noort, J. W. Drijfhout, R. Offringa, A. Holmgren, and T. H. M. Ottenhoff, "Purification and functional analysis of the Mycobacterium leprae thioredoxin/thioredoxin reductase hybrid protein," The Journal of Biological Chemistry, vol. 270, no. 43, pp. 25604-25606, 1995.

[59] N. Esaguy and A. P. Águas, "Subcellular localization of the 65$\mathrm{kDa}$ heat shock protein in mycobacteria by immunoblotting and immunogold ultracytochemistry," Journal of Submicroscopic Cytology and Pathology, vol. 29, no. 1, pp. 85-90, 1997.

[60] L. H. Sampaio, M. M. A. Stefani, R. M. Oliveira et al., "Immunologically reactive $M$. leprae antigens with relevance to diagnosis and vaccine development," BMC Infectious Diseases, vol. 11, article 26, 2011.

[61] A. Geluk, M. S. Duthie, and J. S. Spencer, "Postgenomic Mycobacterium leprae antigens for cellular and serological diagnosis of $M$. leprae exposure, infection and leprosy disease," Leprosy Review, vol. 82, no. 4, pp. 402-421, 2011.

[62] R. Aráoz, N. Honoré, S. Cho et al., "Antigen discovery: a postgenomic approach to leprosy diagnosis," Infection and Immunity, vol. 74, no. 1, pp. 175-182, 2006.

[63] K. Bobosha, J. J. van der Ploeg-Van Schip, D. A. Esquenazi et al., "Peptides derived from Mycobacterium leprae ML1601c discriminate between leprosy patients and healthy endemic controls," Journal of Tropical Medicine, vol. 2012, Article ID 132049, 11 pages, 2012.

[64] K. Bobosha, J. J. van der Ploeg-Van Schip, M. Zewdie et al., "Immunogenicity of Mycobacterium leprae unique antigens in leprosy endemic populations in Asia and Africa," Leprosy Review, vol. 82, no. 4, pp. 445-458, 2011.

[65] A. Geluk, J. van der Ploeg, R. O. B. Teles et al., "Rational combination of peptides derived from different Mycobacterium leprae proteins improves sensitivity for immunodiagnosis of $M$. leprae infection," Clinical and Vaccine Immunology, vol. 15, no. 3, pp. 522-533, 2008.

[66] K. Bobosha, S. T. Tang, J. J. van der Ploeg-van schip et al., "Mycobacterium leprae virulence-associated peptides are indicators of exposure to M. leprae in Brazil, Ethiopia and Nepal," Memorias do Instituto Oswaldo Cruz, Rio De Janeiro, vol. 107, supplement 1, pp. 112-123, 2012.

[67] D. S. Ridley and W. H. Jopling, "Classification of leprosy according to immunity. A five-group system," International 
Journal of Leprosy and Other Mycobacterial Diseases, vol. 34, no. 3, pp. 255-273, 1966.

[68] WHO, "WHO and NLEP report on "Guide to eliminate leprosy as a public health problem"', WHO/CDS/CPE/CEE/2000.14, International Leprosy Elimination Group, World Health Organization, Geneva, Switzerland, 2000.

[69] O. Parkash, A. Kumar, R. Pandey, A. Nigam, and B. K. Girdhar, "Performance of a lateral flow test for the detection of leprosy patients in India," Journal of Medical Microbiology, vol. 57, no. 1, pp. 130-132, 2008.

[70] A. Kumar, B. K. Girdhar, and O. Parkash, "Immunoproteomic analysis of Mycobacterium leprae derived cell membrane antigens," International Journal of Biological \& Medical Research, vol. 1, no. 4, pp. 242-247, 2010.

[71] E. M. Hungria, R. M. de Oliveira, A. L. O. M. de Souza et al., "Seroreactivity to new Mycobacterium leprae protein antigens in different leprosy-endemic regions in Brazil," Memorias do Instituto Oswaldo Cruz, vol. 107, supplement 1, pp. 104-111, 2012. 


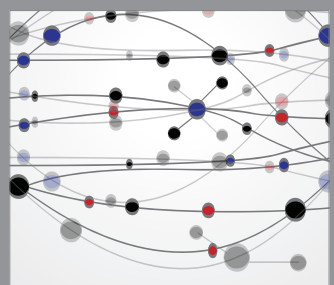

The Scientific World Journal
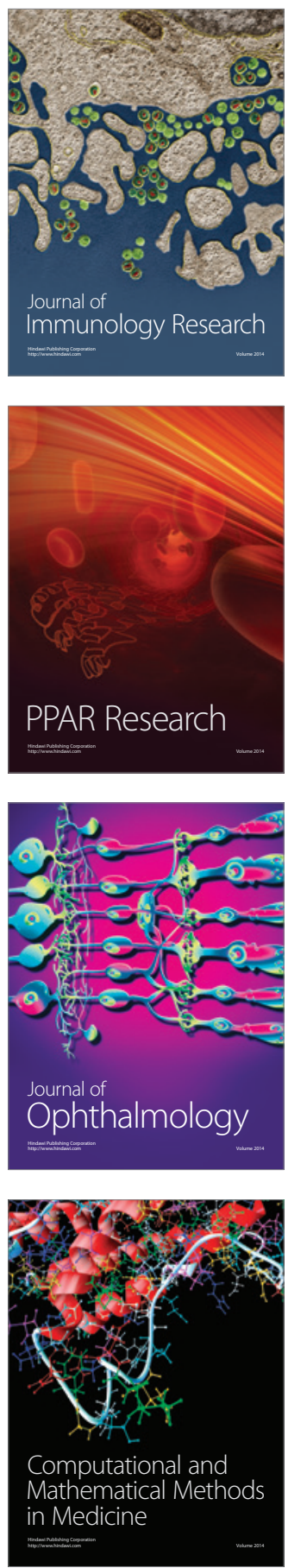

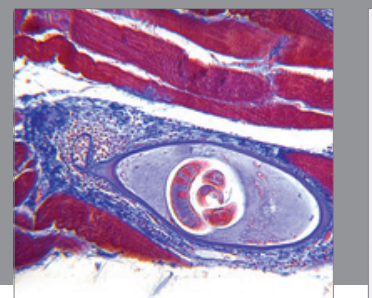

Gastroenterology

Research and Practice
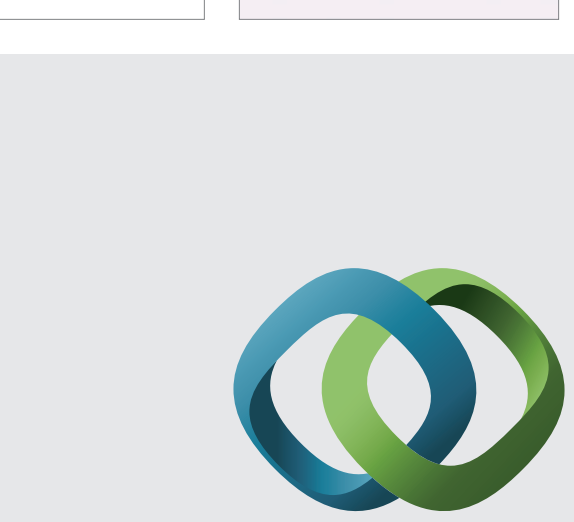

\section{Hindawi}

Submit your manuscripts at

http://www.hindawi.com
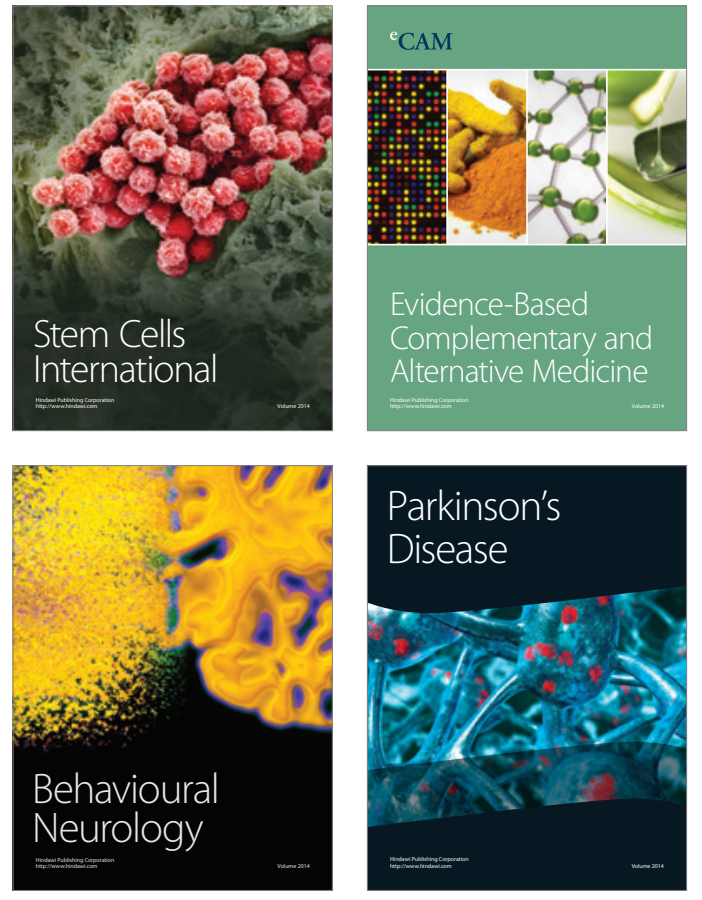
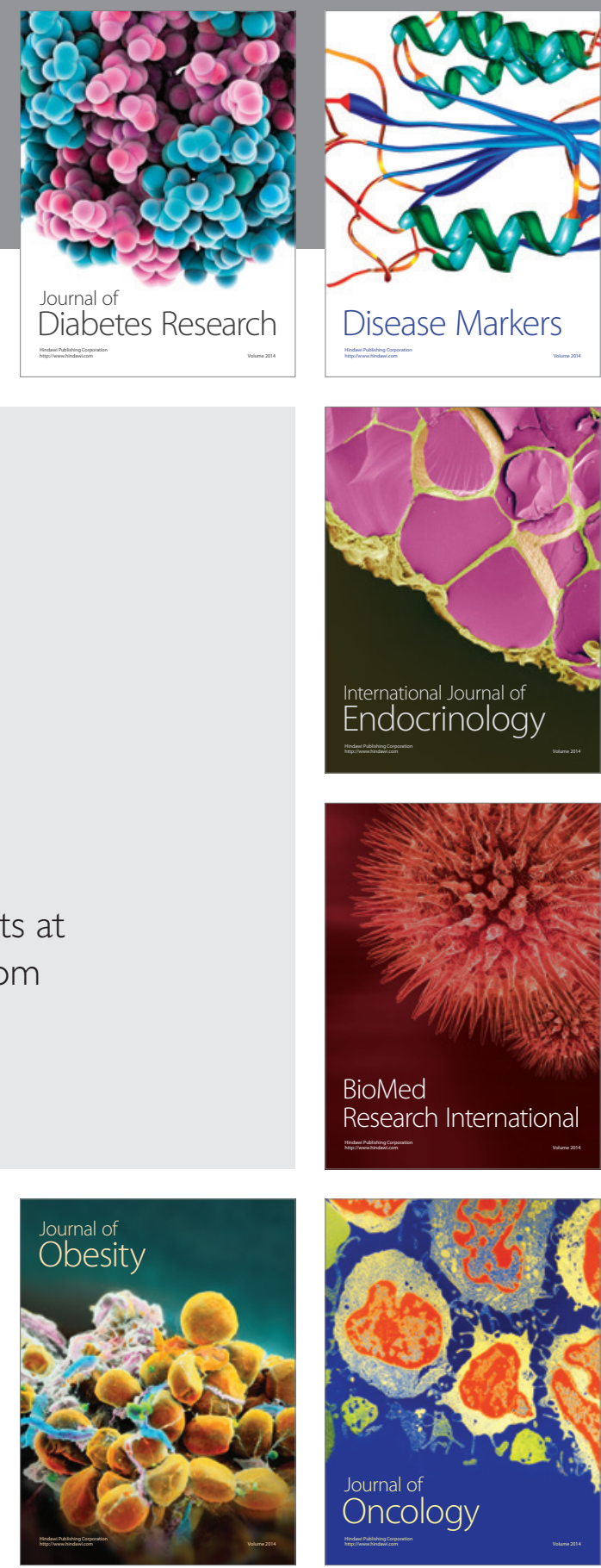

Disease Markers
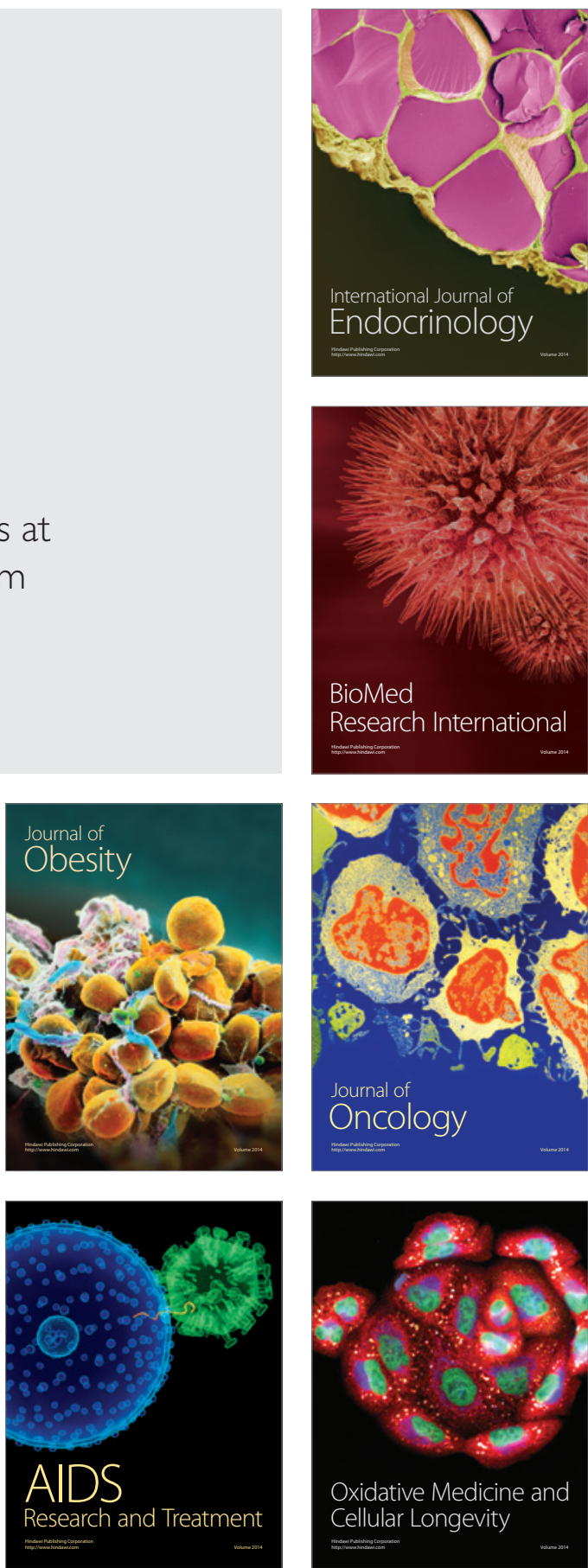